\title{
Definition of ICESat Selection Criteria for Their Use as Height References for TanDEM-X
}

\author{
Jaime Hueso González, Markus Bachmann, Rolf Scheiber, and Gerhard Krieger, Senior Member, IEEE
}

\begin{abstract}
The TanDEM-X satellite synthetic aperture radar (SAR) mission, which is the result of the partnership between the German Aerospace Center (DLR) and Astrium GmbH, has the goal to deliver a high-precision global digital elevation model (DEM). The X-band SAR interferometry-derived DEMs contain absolute and relative height errors that have to be minimized with the help of height references in order to achieve the specified accuracies. ICESat laser altimetry data are suited for this task, due to their accuracy and global distribution. In order to gain experience in the comparison between a radar-derived DEM and ICESat GLA14 elevation data, an X-band DEM was acquired over a test region with the experimental airborne radar system of DLR in Oberpfaffenhofen. Additionally, a laser DEM of the area was used to verify the height accuracy claimed by previously published ICESat studies over different terrain types and after applying different selection threshold criteria. The analyses described in this paper are the basis for the definition of a suitable global ICESat selection strategy and include the computation of the density of selected ICESat samples over the Earth. These aspects are crucial for a successful TanDEM-X DEM generation.
\end{abstract}

Index Terms-Digital elevation model (DEM) calibration, experimental airborne radar system (E-SAR), ICESat, laser DEM, synthetic aperture radar (SAR) interferometry (InSAR), TanDEM-X.

\section{INTRODUCTION}

$\mathbf{I}$ N THE first half of 2010, TanDEM-X [1] will be launched to join its twin satellite TerraSAR-X, which has been in orbit since June 2007. Both satellites will orbit in a closely controlled helix formation in order to acquire accurate crosstrack synthetic aperture radar (SAR) interferograms over the whole of Earth's land surface. The objective is to deliver, within four years after the launch, a global digital elevation model (DEM) with an unprecedented combination of coverage and height accuracy.

The demanding TanDEM-X height-accuracy requirements [1] are listed in Table I. They have to be fulfilled at $90 \%$ of the land surface with 12-m horizontal resolution (independent posting).

The TanDEM-X SAR interferometry (InSAR) DEM represents the heights of the reflected surface. Typically for $\mathrm{X}$-band, this corresponds to the actual ground elevation over a bald land. For vegetated areas, it provides the heights around

Manuscript received February 25, 2009; revised November 3, 2009 and December 21, 2009. Date of publication March 25, 2010; date of current version May 19, 2010. This work was supported in part by the German Federal Ministry for Economics and Technology (Förderkennzeichen 50 EE 0601).

The authors are with the Microwaves and Radar Institute, German Aerospace Center (DLR), 82234 Wessling, Germany (e-mail: jaime.hueso@dlr.de; markus.bachmann@dlr.de; rolf.scheiber@dlr.de; gerhard.krieger@dlr.de).

Digital Object Identifier 10.1109/TGRS.2010.2041355
TABLE I

TANDEM-X DEM SPECIFICATIONS

\begin{tabular}{|l|l|l|}
\hline Requirement & Specification & Accuracy \\
\hline $\begin{array}{l}\text { Absolute vertical accuracy } \\
(\text { global })\end{array}$ & $90 \%$ linear error & $10 \mathrm{~m}$ \\
\hline $\begin{array}{l}\text { Relative vertical accuracy } \\
(100 \mathrm{~km} \times 100 \mathrm{~km})\end{array}$ & $\begin{array}{l}90 \% \text { linear point- } \\
\text { to-point error }\end{array}$ & $\begin{array}{l}2 \mathrm{~m}(\mathrm{slope}<20 \%) \\
4 \mathrm{~m}(\text { slope }>20 \%)\end{array}$ \\
\hline
\end{tabular}

the top of the canopy, depending on the density of the particular vegetation type and on the characteristic penetration depth of $\mathrm{X}$-band signals in it. Hence, when talking about height errors, differences between the actual TanDEM-X DEM height values and the ones of the reflected surface measured by an ideal $\mathrm{X}$-band interferometer are meant.

The InSAR DEMs directly delivered by the TanDEM-X interferometric processor are called raw DEMs. Although the satellite SAR instruments are precisely calibrated, residual-error sources remain, resulting in raw DEMs affected by both systematic and quickly varying (noiselike) height errors [2]. The systematic error components, which are typically slowly varying ramps (height-error variation $\ll 0.01 \mathrm{~m} / \mathrm{km}_{\text {ground distance }}$ ) in the raw DEM, can be corrected by using independent height calibration information. Hence, well-distributed and accurate height references are needed. On the one hand, these references correct constant absolute height errors by shifting the raw DEMs by a constant vertical value. On the other hand, and in combination with tie points (i.e., information provided by partially overlapping raw DEMs) [2], they minimize the systematic relative height point-to-point errors within each raw DEM by means of a 2-D polynomial height correction model, whose coefficients are derived by a least-squares method. Since the height-reference information is propagated to the neighbors by applying the tie points, it is not necessary to have height references over all raw DEMs, but only over some in the complete adjustment scene. In [2], simulation examples and height-reference distributions are shown. This DEM-calibration process generates the final DEM product.

This paper briefly presents the demanding requirements of the TanDEM-X mission for the height references and justifies the choice of ICESat Geoscience Laser Altimeter System (GLAS) laser altimeter data (see [3] and [4]) as the main reference source. The main motivation of this paper is the identification of an appropriate selection strategy for ICESat data by comparing its height values with several independent DEMs. Only in this way, the height accuracy required by TanDEM-X can be reached.

In Section II, it is explained why ICESat data are well suited for an accurate height referencing of the TanDEM-X DEM. 
ICESat product properties and height accuracy over various reference surfaces have been studied and verified in several previous publications [5]-[8], and here, a summary of these characteristics is given.

In order to simulate the operational TanDEM-X DEM calibration, a test region was acquired in bistatic mode with the experimental airborne radar system (E-SAR) of DLR in Oberpfaffenhofen. This is described in Section III, where the comparison of the ICESat heights over the test region with Shuttle Radar Topography Mission (SRTM) [9] and with a laser DEM (Landesamt für Vermessung und Geoinformation Bayern) is also presented.

The SRTM heights serve for the identification of ICESat outliers, and the laser DEM gives an estimation of the height accuracy of the selected ICESat points. Several authors, like Duong et al. [10], have analyzed the ICESat echo waveforms and height accuracies and suggested some rules to discard low-quality ICESat samples and outliers. The innovation in this paper is the identification of practical and more restrictive selection criteria to achieve a target accuracy that is compliant with the TanDEM-X requirements and their application on a global scale. The resulting density of selected ICESat points over the Earth's surface and the list of criteria are shown in Sections III-D and III-E.

The conclusion of the experiments and of the heightreference selection effort is included in Section IV.

\section{Height ReFERENCES-ICES AT}

The most critical height requirement in Table I is the 2-m relative height (90\% confidence). The error sources that affect the TanDEM-X raw DEMs can be classified into noiselike and systematic errors. Noiselike errors like performance losses, which cannot be corrected by systematic functional models, almost exhaust the entire relative height-error budget [1], only leaving $0.53-\mathrm{m}$ ( $1 \sigma$, assuming a Gaussian error) margin [2] for the remaining contributions. This margin is exceeded by the systematic height errors [2], resulting in a noncompliance of the relative height-error requirement in $100 \mathrm{~km} \times 100 \mathrm{~km}$ regions.

Therefore, the goal of the TanDEM-X DEM calibration is the reduction of the systematic height-error components below the $0.53-\mathrm{m}(1 \sigma)$ limit within regions of this size. This can be achieved with height references having accuracies better than $0.53 \mathrm{~m}(1 \sigma)$, as shown in the simulations in [2], assuming that they have no systematic error trend. The challenge faced in this paper is the identification of globally distributed height references with this demanding precision.

Nevertheless, it has to be noted that slightly less accurate height references could also have a good adjustment performance, as the goal is to adjust low-frequency height-error changes. In fact, usually several height references are averaged to serve as height calibration, with the corresponding precision improvement. The availability of such height references for the DEM calibration implies at the same time a broad fulfillment of the absolute height accuracy of $10 \mathrm{~m}$ (cf. Table I and [2]).

Accordingly, all the ground-control-point databases considered by the TanDEM-X mission and their accuracy are summarized in Table II.
TABLE II

HeIGHT REFERENCES AND ACCURACIES FOR TANDEM-X

\begin{tabular}{|c|c|c|c|}
\hline Function & GCP source & Coverage & Height accuracy \\
\hline $\begin{array}{l}\text { COARSE } \\
\text { absolute } \\
\text { calibration }\end{array}$ & $\begin{array}{l}\text { Absolute phase } \\
\text { or SRTM [9] }\end{array}$ & $\begin{array}{l}\text { C-Band: global } \\
\text { X-Band: global } \\
\text { with big gaps }\end{array}$ & $\begin{array}{l}\text { SRTM }(90 \%) \\
\sim 7 \mathbf{~ m} \text { absolute } \\
\sim \mathbf{8} \text { m relative }\end{array}$ \\
\hline $\begin{array}{l}\text { MAIN absolute } \\
\text { and relative cal. }\end{array}$ & ICESat & Global & 0.1 m - 1 m $(1 \sigma)$ \\
\hline $\begin{array}{l}\text { SECONDARY } \\
\text { absolute and } \\
\text { relative cal. }\end{array}$ & $\begin{array}{l}\text { Lidar/Airborne } \\
\text { DEM }\end{array}$ & Local & $\begin{array}{l}0.1 \mathrm{~m}-0.5 \mathrm{~m} \\
(1 \sigma)\end{array}$ \\
\hline VALIDATION & GPS tracks & Selected regions & $0.5 \mathrm{~m}(1 \sigma)$ \\
\hline
\end{tabular}

In the first step of the DEM generation, the interferograms are unwrapped and the absolute phase is determined by means of algorithms like Delta-K [11], provided that the TanDEM-X system confirms its expected phase stability. As a fallback solution, SRTM can be applied for this absolute phase referencing.

ICESat has been selected as the main provider of height references for the TanDEM-X DEM calibration. The ICESat spaceborne laser altimeter GLAS [3] sends pulses of around 5-6-ns width at a $40-\mathrm{Hz}$ rate, which result in samples with 172-m along-track spacing on the Earth's surface. Its polar orbit provides good global coverage for hooking in the DEM. ICESat elevation data can optimally reach an accuracy on the order of $0.1 \mathrm{~m}(1 \sigma)$ for flat bald locations, according to several accuracy assessments in the literature and the ICESat requirements. In irregular or vegetated surfaces, the laser echo is dispersed by the different contributions within the laser footprint, and the height accuracy can degrade to values on the order of $1 \mathrm{~m}(1 \sigma)$. ICESat outliers due to cloud reflections or saturated waveforms are not considered in this accuracy estimation. This means that selection criteria are needed for ICESat samples to achieve the $0.53-\mathrm{m}(1 \sigma)$ height accuracy on a global scale.

The GLA14 data structure provides the centroid height of each return echo. Additionally, it offers information related to the return pulse characteristics and the measurement conditions, which assists in the identification of these selection criteria. The principal parameters of the data structure are the number of Gaussian peaks (pk) needed to model the returned echo, the pulses' semiwidth of each peak $(\sigma)$, the surface slope and roughness, the cloud layers, the pulse energy, and the surface type-land, water, ice, or sea ice. Additionally, information about the vegetation coverage for each point is obtained from the Moderate Resolution Imaging Spectroradiometer (MODIS) database $^{1}$ [12], as done in [5].

In Fig. 1, some examples of the return-echo pulse models are shown, where a clear dependence between the terrain type and the pulse envelope shape (number of Gaussian peaks and their width) can be identified. This had been already observed and studied by Carabajal and Harding [5] in relation with the SRTM DEM roughness. The ground region marked in red in Fig. 1 represents the typical slightly elliptical laser footprint of ICESat. Depending on the campaign, ICESat used different lasers for the altimetry measurements, each one having a characteristic footprint shape. The footprint dimensions are listed in [13], and the nature of the weighting function is described in [3]. Although the analysis in this paper takes into account

\footnotetext{
${ }^{1}$ Data available at http://www.landcover.org
} 


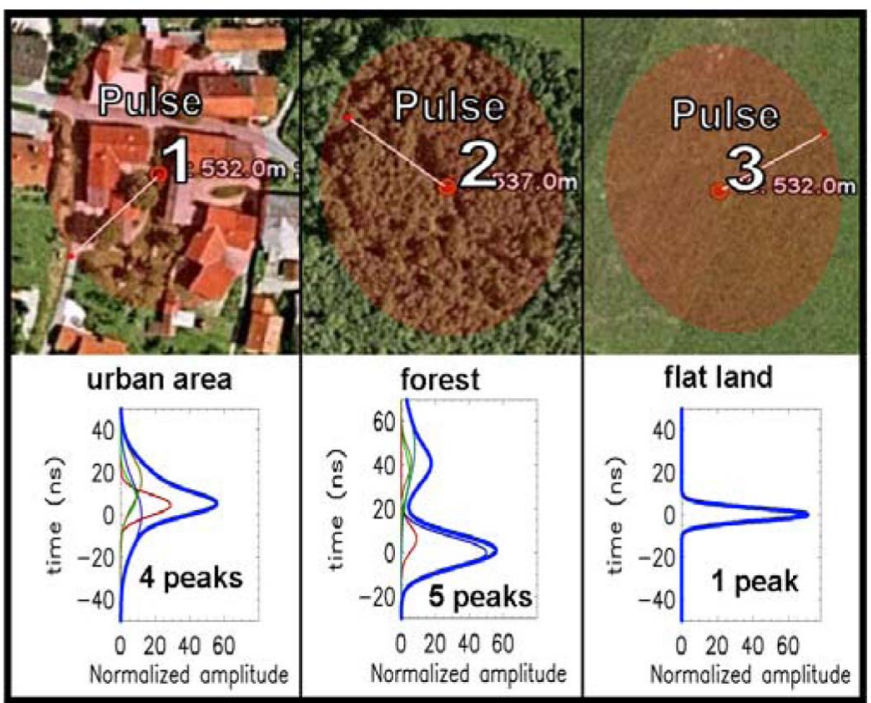

Fig. 1. ICESat return echoes from different terrain types. Laser footprint is highlighted in red. Blue line is the total echo amplitude envelope.

the exact laser footprint of each sample, circular footprints with the corresponding equivalent radii are also a good average approximation.

The height noted in the GLA14 product for each ICESat point is a combination of the real laser height values within its footprint, averaged by the laser power distribution. Only echo pulses coming from flat surfaces are modeled with a single narrow Gaussian peak. Forests and urban areas, on the contrary, show more complex echo shapes. The envelope of pulse 2 shows the typical forest return, with the first reflection on the tree top and a ground echo.

For complex return pulses, the centroid height represents a vertical average cell height. More complex calculations are needed to extract the ground height or the "X-band-like" height that would be suited for the TanDEM-X DEM. The discrepancies between the X-band phase center and the reflected echo of a laser pulse depend also on the tree category. The insufficient knowledge of the vegetation coverage on a global scale and the considerable additional processing effort makes this option impracticable for TanDEM-X. The proposed solution is to filter out ICESat returns from vegetated surfaces, as explained in the following sections. This still provides a sufficient global density of selected ICESat references for the DEM calibration.

In addition to global databases like ICESat, other local references or DEMs are foreseen as a backup solution. They are usually more accurate and expensive than global sources, but can be useful for obtaining additional height accuracy over certain regions or to cover potential spots of low quality/density ICESat data. GPS tracks are used to verify the final DEM accuracies.

\section{ICESAT-DEM COMPARISON}

\section{A. Test Description and Reference DEMs}

A test region located in the southeast of Munich, close to Miesbach, was chosen for this study. Several parallel ICESat GLA14 tracks, from autumn 2003 to autumn 2007, release 428, cover its full length from north to south, offering a large amount of points for the comparison. In addition, one track crosses the others diagonally. The test region combines flat land in the north with forests and mountainous areas in the south, in order to enable the identification of dependencies from the terrain type.

Several reference DEMs over the Miesbach test region were compared with the ICESat sample heights. A very accurate laser DEM (Landesamt für Vermessung und Geoinformation Bayern) with a height accuracy better than $0.5 \mathrm{~m}$ was chosen. The expected ICESat height accuracy over the whole test site is up to $1 \mathrm{~m}(1 \sigma)$, without taking into account potential outliers. Therefore, the laser DEM is suited for the verification of the ICESat accuracy and the derivation of selection criteria for the TanDEM-X mission.

The second available DEM is the one acquired with the airborne E-SAR [14] system of DLR. One of the goals of comparing this DEM to the ICESat data points is to experimentally validate the DEM-calibration strategy envisioned for TanDEM-X. Therefore, it reproduces the TanDEM-X interferometric acquisition conditions as closely as possible. The characteristics and distribution of the antennas on the airplane allow for single-pass cross-track interferometry at X-band. The E-SAR DEM relative height accuracy is on the order of $0.5-$ $1.0 \mathrm{~m}$, and the retrieved absolute heights are usually accurate within $\pm 2 \mathrm{~m}$ in a terrain with moderate topography. However, some forested areas have been identified with wrong phase unwrapping offsets and were excluded from subsequent analyses. The horizontal resolution of the computed E-SAR DEM is $5 \mathrm{~m}$. The comparison of the E-SAR X-band heights with the laser altimeter references points out the different reflection mechanisms of both frequencies over certain terrain types. The same discrepancies are expected in the TanDEM-X DEM.

The last reference DEM is the SRTM C-band DEM [9], which is included in the GLA14 product. This reference height source has $90-\mathrm{m}$ resolution, and its average accuracy is listed in Table II. Concretely in the Eurasia region, the absolute height error is $6.2 \mathrm{~m}$, and the relative one $8.7 \mathrm{~m}$ at $90 \%$ confidence [9]. The SRTM DEM coverage and its sufficient accuracy make this reference suitable for removing ICESat outliers, as will be tested in the Miesbach test region.

All comparisons were done taking as reference the WGS84 ellipsoid. Hence, ICESat heights were converted to this system from the TOPEX reference ellipsoid. Since the DEM posting is smaller than the ICESat footprint dimension, DEM heights have to be averaged in order to fit the corresponding ICESat footprint and have a valid comparison. In this analysis, the DEM averaged heights are calculated as a weighted mean of the DEM samples according to the ICESat footprint power models suggested in [3] and [13].

The main results of these comparisons are described in the following sections.

\section{B. ICESat Samples Suited for DEM Calibration}

Some ICESat points are not suited for DEM calibration (see, e.g., [8] and [10]) and shall be discarded before any subsequent height comparison: outliers due to bad acquisition conditions and samples in locations where the DEM to calibrate has low quality. 
On the one hand, ICESat outliers due to bad acquisition conditions, like cloud reflections or laser pulse saturations, can be theoretically detected by analyzing the information of the ICESat data structure. However, the cloud coverage flags present in the GLA14 products over the test site under study showed inconsistencies and could not be used for this task. Additional ICESat cloud data products (GLA06-GLA11) are more reliable for cloud reflection detection, as suggested by Atwood et al. [8] and Duong et al. [10]. However, the additional complexity of extracting and interpreting additional products, as well as correlating them with the GLA14 product, is quite substantial. Therefore, a simpler alternative was adopted for the TanDEM$\mathrm{X}$ mission, which consists of comparing ICESat with SRTM C-band DEM heights, like, for example, in [5]. Differences exceeding $200 \mathrm{~m}$ and even reaching $1200 \mathrm{~m}$ were detected for the Miesbach test region. A height difference threshold of $50 \mathrm{~m}$ has been set for the TanDEM-X mission. However, the SRTM C-band DEM has a limited coverage, between $60^{\circ} \mathrm{N}$ and $54^{\circ} \mathrm{S}$; hence, this method cannot be applied in Polar Regions. Here, the solution is to use uncalibrated TanDEM-X raw DEMs. Each difference between ICESat and the raw DEM is compared to the neighboring differences, detecting in this way the outliers. The risk of eliminating valid points is compensated by the fact that the ICESat sample density is much bigger at extreme latitudes. A similar strategy is implemented in [6] and [10], where the heights of the DEM under test and several averaging and statistical techniques are applied to detect big height differences.

The described approaches may not detect echoes affected by low clouds or fog, which could lie below the 50-m threshold. However, it has been observed that cloud reflections have a very broad return-echo shape. Therefore, potential remaining outliers from low clouds are anyway eliminated when applying the basic ICESat selection criteria that are introduced in the following sections.

On the other hand, even high-quality ICESat samples, if applied in locations of the raw DEM where there is very low coherence, shadowing or layover effects, or phase unwrapping errors, can lead to DEM-calibration errors.

In [8], a water and ice mask is used to locate low-coherence regions. The same is done in TanDEM-X, where a coherence map and a water mask are always provided with each raw DEM. Furthermore, phase unwrapping errors are minimized during the TanDEM-X DEM processing; thus, this problem has not to be faced in the DEM calibration [2].

These rules provide the set of ICESat points that are suited for DEM calibration. Previous ICESat quality studies in the literature propose similar selection methods, concentrating on quality flags provided by the ICESat data structure. As an example, [10] discards samples with active "saturation" and "invalid elevation" and "cloud reflection" flags. If the underlying DEM has too many invalid points within the laser footprint, this sample is also eliminated.

However, even after applying all these methods, the ICESat accuracy can be worse than the TanDEM-X height-reference requirement of $0.53 \mathrm{~m}$, as explained in Section II. As the objective of this paper is to achieve a concrete height-accuracy goal, quantitative selection criteria are sought that can identify
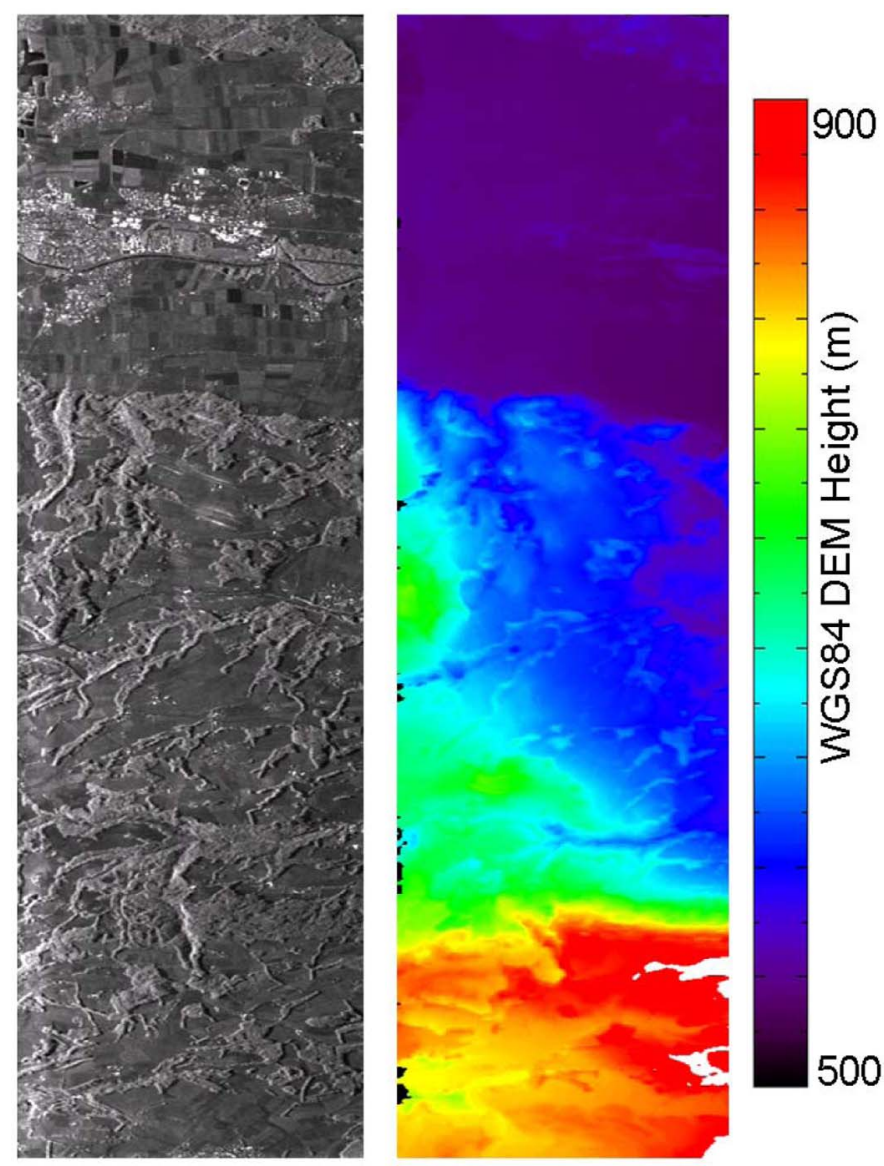

Fig. 2. Miesbach E-SAR SAR image and DEM. Center coordinates: $\mathrm{N} 47^{\circ} 49^{\prime}, \mathrm{E} 11^{\circ} 58^{\prime}$

more refined subsets of ICESat points with an optimal height accuracy on a global scale. This is only possible by studying in detail the height accuracy of ICESat in relation with the echo pulse characteristics, based on the comparison with the reference DEMs.

The following sections show the different selection mechanisms studied to achieve this and the accuracy of the selected ICESat sample sets over different terrain types.

\section{Comparison Statistics}

1) Analyses Over Different Terrain Types: One of the goals of these experiments is to test how the ICESat height references can be applied to an X-band InSAR-derived DEM. The E-SAR DEM is useful for this purpose. The E-SAR SAR image and DEM are shown in Fig. 2, where the different terrain types can be clearly identified.

Additionally, the laser DEM over the same region provides a very precise height reference, with its $0.5-\mathrm{m}$ accuracy in flat areas. The laser DEM plot and the height differences with the ICESat samples are shown in Fig. 3.

Table III shows the height difference of the ICESat samples (all except the $3 \%$ outliers) with the different DEMs, sorted according to the terrain types: "flat," "forest," and "mountain". Finally, the last column includes the height differences of all the ICESat points. The total number of ICESat points contained in the E-SAR DEM is smaller than in the laser DEM, because the 


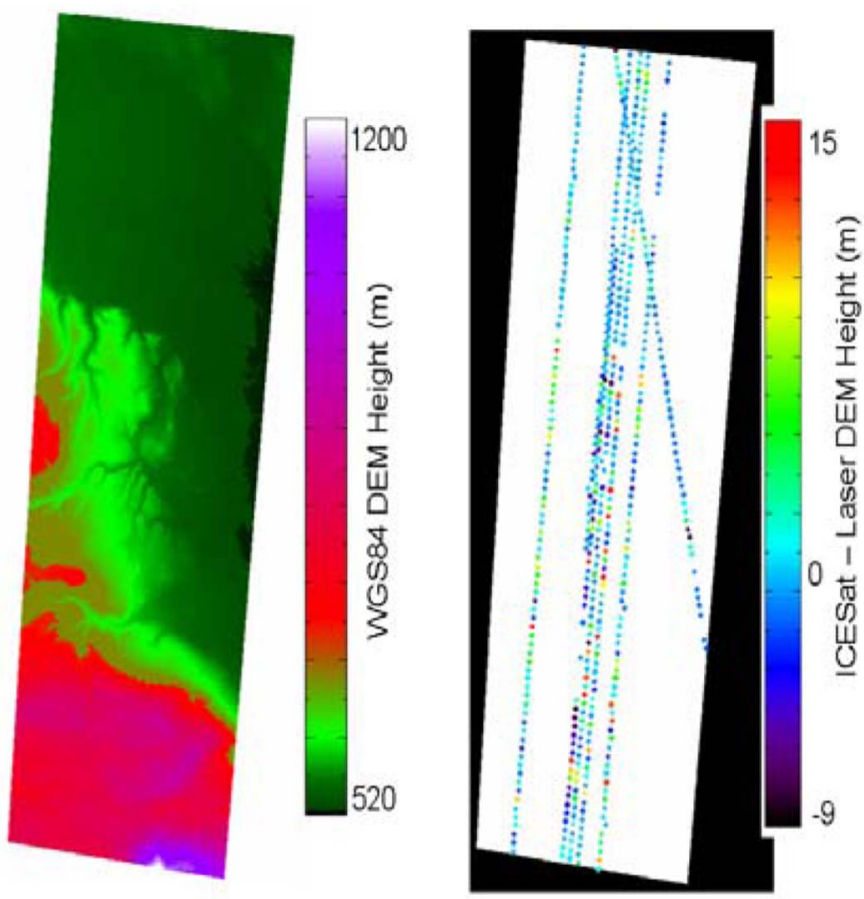

Fig. 3. Laser DEM over Miesbach, Germany, and difference with ICESat samples. Outliers have been already eliminated.

TABLE III

HEIGHT DIFFERENCES ICESAT-DEMs OVER DIFFERENT TERRAIN TYPES

\begin{tabular}{|c|c|c|c|c|c|}
\hline \multirow{2}{*}{\multicolumn{2}{|c|}{ Reference DEM }} & \multicolumn{4}{|c|}{ Terrain Type } \\
\hline & & \multirow{2}{*}{$\begin{array}{c}\text { Flat land } \\
-0.65 \mathrm{~m}\end{array}$} & \multirow{2}{*}{$\frac{\text { Forest }}{5.8 \mathrm{~m}}$} & \multirow{2}{*}{$\begin{array}{c}\text { Mountain } \\
0.66 \mathrm{~m}\end{array}$} & \multirow{2}{*}{$\frac{\text { All }}{1.39 \mathrm{~m}}$} \\
\hline \multirow{3}{*}{ Laser } & Mean & & & & \\
\hline & StdDev $(1 \sigma)$ & $2.87 \mathrm{~m}$ & $9.48 \mathrm{~m}$ & $4.74 \mathrm{~m}$ & $6.56 \mathrm{~m}$ \\
\hline & Nr. points / \% & $288 / 49 \%$ & $159 / 27 \%$ & $123 / 21 \%$ & $570 / 97 \%$ \\
\hline \multirow{3}{*}{ E-SAR } & Mean & $-3.9 m$ & $-6.6 m$ & $-4.9 m$ & $-4.82 m$ \\
\hline & $\operatorname{StdDev}(1 \sigma)$ & $4.58 \mathrm{~m}$ & $10.3 m$ & $10.5 \mathrm{~m}$ & $6.7 \mathrm{~m}$ \\
\hline & Nr. points $/ \%$ & $155 / 48 \%$ & $93 / 29 \%$ & $68 / 21 \%$ & $316 / 98 \%$ \\
\hline \multirow{3}{*}{$\begin{array}{l}\text { SRTM } \\
\text { C-band }\end{array}$} & Mean & $-0.33 \mathrm{~m}$ & $-1 \mathrm{~m}$ & $-2.5 \mathrm{~m}$ & $-0.96 \mathrm{~m}$ \\
\hline & $\operatorname{StdDev}(1 \sigma)$ & $4.68 \mathrm{~m}$ & $9.1 \mathrm{~m}$ & $8.5 \mathrm{~m}$ & $6.68 \mathrm{~m}$ \\
\hline & Nr. points $/ \%$ & $288 / 49 \%$ & $159 / 27 \%$ & $123 / 21 \%$ & $570 / 97 \%$ \\
\hline
\end{tabular}

E-SAR DEM is slightly narrower, and its shadow and phase unwrapping error regions have been discarded for the analysis.

As expected, the smallest differences appear in the comparison with the laser DEM. The accuracy over flat land reaches $2.87 \mathrm{~m}$ (with a standard deviation of $1 \sigma$ ), the one over forest $9.48 \mathrm{~m}$, and over mountains $4.74 \mathrm{~m}$. On the other hand, the E-SAR DEM standard deviation is slightly worse: $4.58 \mathrm{~m}$ over flat land, $10.3 \mathrm{~m}$ over forest, and $10.5 \mathrm{~m}$ over mountains.

The mean differences between the laser DEM and ICESat data stay close to $0 \mathrm{~m}$, except for the forested areas, where the mean difference is close to $6 \mathrm{~m}$ and the relative accuracy is around $9.5 \mathrm{~m}$. This relatively high discrepancy in the mean height of forested areas of $6 \mathrm{~m}$ is still unclear, but it might be caused by laser DEM processing error precisely in the forested area. In the comparison with the SRTM and the E-SAR DEMs, the mean height difference with ICESat stays relatively constant over all terrain types.

The overall -4.8-m offset of the E-SAR DEM is due to the way the nominal height values are calculated in ICESat. While the E-SAR DEM phase center is located close to the top of the

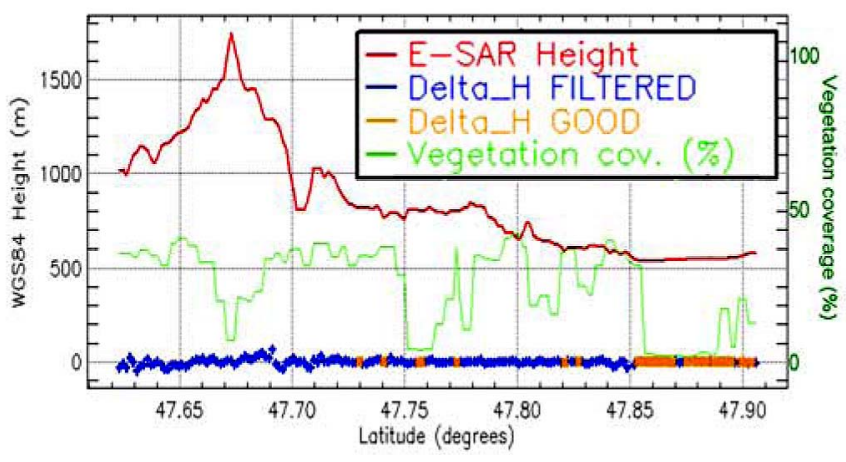

Fig. 4. Height values of the E-SAR DEM and difference with ICESat samples of spring 2004 .

canopy, the ICESat heights provide a centroid height value, a combination between the return from the top of the trees and the ground echo. Therefore, the height errors in vegetated areas (or even flat lands with grass or crops) shift the whole E-SAR DEM to bigger heights. Comparing the mean differences of E-SAR with ICESat between flat and forest, it can be observed that this effect is stronger in forests, where the offset is $2.7 \mathrm{~m}$ bigger than that in flat lands. In the following section, selection criteria are applied to select flat land with no vegetation, and there, it can be observed that the mean difference is closer to zero.

An improved height comparison would require a more complex processing of the ICESat heights. This would consist of extracting the height of the first Gaussian component of the return echo. However, this is not foreseen in the TanDEM-X DEM calibration, as anyway the different reflection mechanisms between X-band and laser frequencies would cause intrinsic height errors.

The standard deviations are also big for mountainous areas (4.74 $\mathrm{m}$ for the laser DEM). This is not dramatic, as the laser DEM accuracy itself is smaller for this terrain and the relative height requirements for TanDEM-X in regions with big slopes is more relaxed (cf. Table I).

Another remarkable result from Table III is the relatively high accuracy (better than requirements) of the SRTM data with respect to the ICESat heights. This can be due to the fact that the SRTM-C DEMs over Europe, and especially Germany, are very precisely calibrated with respect to other regions in the world. In forested areas, changes of the canopy over the years may indicate that the laser and E-SAR DEM standard deviations are slightly worse than the SRTM-C DEM.

As a conclusion, only samples from flat land should be applied for the calibration of the TanDEM-X mission on a global scale. Furthermore, a refinement of its quality should be done in order to achieve the accuracy objectives.

2) ICESat Selected Accuracies: On a global scale, where there is a limited knowledge of the different terrain types, general selection criteria should exist in order to refine the ICESat accuracy for a given data set.

Fig. 4 shows one example of a height comparison between an ICESat track and the E-SAR DEM, regardless of the terrain type. As "basic" selection criteria, only echoes with one Gaussian peak and a $\sigma$ of less than 8 ns (which means a pulsewidth $<16 \mathrm{~ns}$ ) were selected as "good" ones and were marked in orange. The points marked in blue belong to echoes that exceeded these thresholds and were "filtered" out. 
TABLE IV

HeIGHT DifFERENCES ICESAT-DEMs ICESAT SETS AFTER APPLICATION OF DIFFERENT SELECTION CRITERIA

\begin{tabular}{|c|c|c|c|c|}
\hline \multirow{2}{*}{\multicolumn{2}{|c|}{ Reference DEM }} & \multicolumn{3}{|c|}{ Selection criteria } \\
\hline & & \multirow{2}{*}{$\begin{array}{l}\text { Basic: } \\
\text { pk=1 and } \\
\sigma<8 \mathrm{~ns} \\
-0.43 \mathrm{~m}\end{array}$} & \multirow{2}{*}{$\begin{array}{c}\text { Extreme: } \\
\text { pk=1 and } \\
\sigma<3.2 \mathrm{~ns}\end{array}$} & \multirow{2}{*}{$\begin{array}{l}\text { Optimal: } \\
\text { pk=1, } \sigma<4.9 \mathrm{~ns} \\
\text { and veg<20\% } \\
-0.66 \mathrm{~m}\end{array}$} \\
\hline \multirow{3}{*}{ Laser } & Mean & & & \\
\hline & StdDev $(1 \sigma)$ & $1.5 \mathrm{~m}$ & $0.17 \mathrm{~m}$ & $0.34 \mathrm{~m}$ \\
\hline & N. points / $\%$ & $165 / 28 \%$ & $24 / 4 \%$ & $88 / 14.9 \%$ \\
\hline \multirow{3}{*}{ E-SAR } & Mean & $-2.5 m$ & $-1.6 \mathrm{~m}$ & $-1.8 m$ \\
\hline & 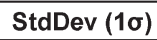 & $3.8 \mathrm{~m}$ & $1.1 \mathrm{~m}$ & $2.8 \mathrm{~m}$ \\
\hline & N. points $/ \%$ & $109 / 34 \%$ & $16 / 5 \%$ & $60 / 18.7 \%$ \\
\hline \multirow{3}{*}{$\begin{array}{l}\text { SRTM- } \\
\text { C Band }\end{array}$} & Mean & $0.3 \mathrm{~m}$ & $1.7 \mathrm{~m}$ & $0.86 \mathrm{~m}$ \\
\hline & StdDev $(1 \sigma)$ & $3.5 \mathrm{~m}$ & $1.05 \mathrm{~m}$ & $1.77 \mathrm{~m}$ \\
\hline & N. points / $\%$ & $165 / 28 \%$ & $24 / 4 \%$ & $88 / 14.9 \%$ \\
\hline
\end{tabular}

As expected, the plot indicates very clearly that flat zones contain most of the good ICESat points. In the southern part of the ICESat track, where the Alps start, the mountainous terrain and the increase in vegetation coverage (cf. green MODIS curve, assigned to the right $y$-axis) result in broader ICESat waveforms. It can also be observed that the spread of the points filtered out is higher than the one of the good points, which demonstrates that, by applying selection criteria, the ICESat height accuracy can be increased for a selected sample set.

A compromise should be taken between achieved accuracy and amount of selected points, which should be sufficient to allow the DEM calibration. With this purpose, two other selection rules have been identified: the "extreme" criteria ( 1 peak and $\sigma<3.2 \mathrm{~ns}$ ) and the "optimal" criteria ( 1 peak, $\sigma<4.9 \mathrm{ns,}$ and vegetation coverage $<20 \%$ ).

All these selection criteria sets exclude return echoes with more than one Gaussian peak. This means that most of the ICESat samples over forested areas are discarded, as suggested in Section III-C-1 for the TanDEM-X mission.

Table IV contains the computed height differences between the sets of ICESat points selected with the described criteria and the different DEMs. Although the only DEM with sufficient accuracy to assess the selected ICESat precision is the laser DEM, the comparison results with the other DEMs have been also included in the table as a reference.

Concentrating on the rows corresponding to the laser DEM comparison, the basic criteria improve the height accuracy of the selected set from 6.56 (Table III) to $1.5 \mathrm{~m}$. Almost $30 \%$ of the available ICESat points fulfill these criteria. Applying the extreme criteria, the accuracy reaches $0.17 \mathrm{~m}$, which fulfills the TanDEM-X requirements for height references.

However, the extreme criteria select only $4 \%$ of the total amount of ICESat points, as only echoes with almost no dispersion with respect to the transmit pulsewidth are chosen. In regions with a low ICESat point density, a relaxation of these criteria may be needed to reach a sufficient number of reference points to calibrate the DEM. This is the intention of the optimal selection criteria, which provide height accuracy within the requirements- $0.34 \mathrm{~m}$ - and an acceptable amount of good points- $15 \%$ of the total number of ICESat points over the region.

In all cases, the mean height differences observed do not exceed the absolute height-error requirement of TanDEM-X

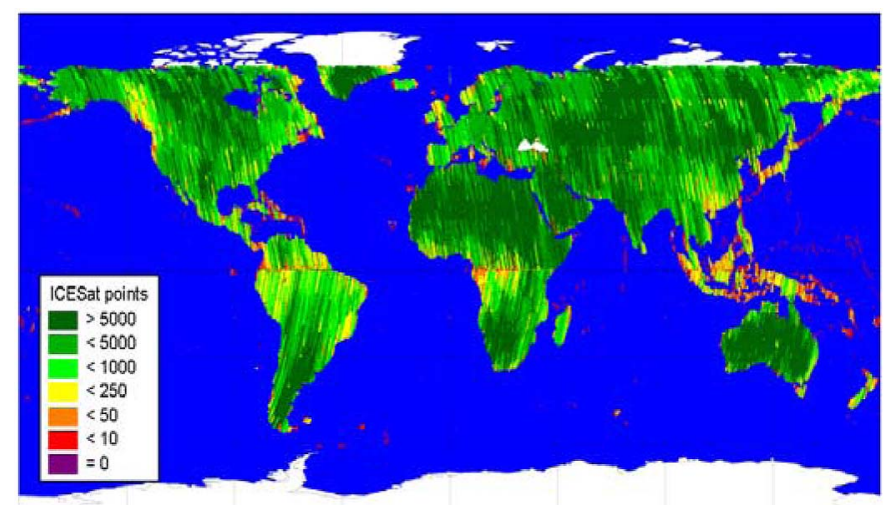

Fig. 5. Global distribution of ICESat points over the proposed TanDEM-X datatakes. Selection with the extreme criteria.

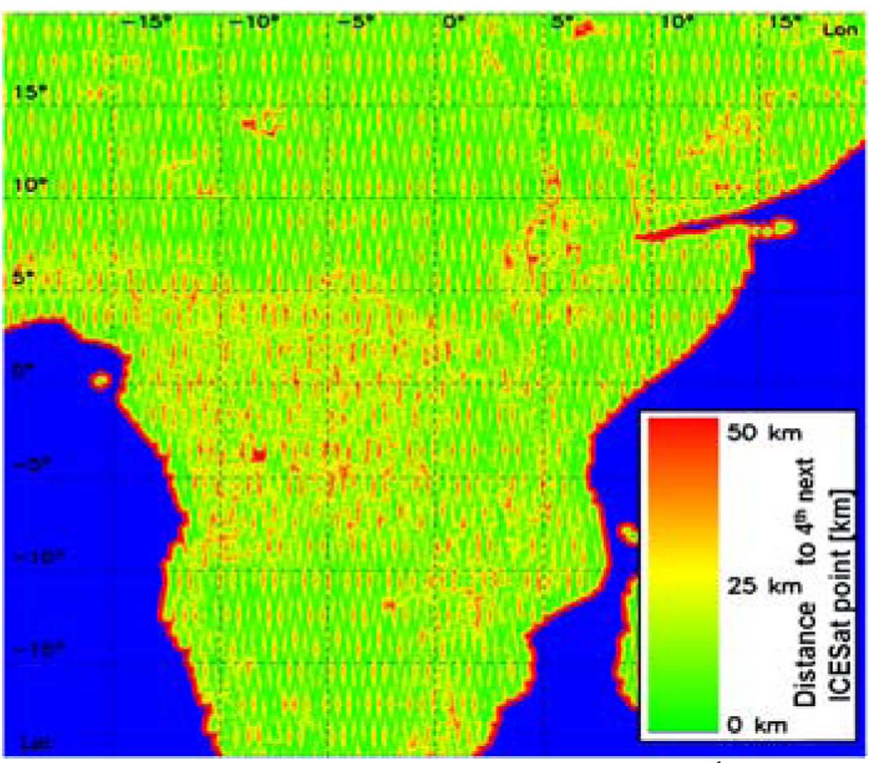

Fig. 6. Minimum distance between ICESat points (the fourth closest neighbor to ensure independent ICESat samples) in equatorial Africa. Selection with the extreme criteria.

and have the tendency to improve when applying the selection criteria.

\section{Global Coverage of Selected Points}

Once ICESat selection criteria have been identified, the global coverage of the selected samples has to be investigated. Special attention has to be given to regions with a low density and/or irregular distribution of selected ICESat points, where the estimation quality of the 2-D height-error correction functions for each raw DEM decreases.

Fig. 5 depicts, on a global scale, the regions covered by each TanDEM-X acquisition (datatake) coded with a color representing the number of good quality ICESat points that it contains.

The length and distribution of the datatakes in Fig. 5 correspond with the actual proposed TanDEM-X acquisition plan and timeline from December 2008. The ICESat points have been selected according to the extreme criteria, which is a worst case in terms of ICESat coverage. 
The results in Fig. 5 point out that most of the TanDEM-X datatakes are covered by several hundred high-quality ICESat calibration points. Even datatakes over critical mountainous regions like the Himalayas have high-density values, since parts of the long datatakes also cover flat landscape. Only some problematic regions remain, like areas close to the equator and isolated islands. At the equator, adjacent ICESat tracks have a maximal ground separation of around $80 \mathrm{~km}$. Tropical forests are also present there, which means more dispersive echoes and a reduced percentage of selected points.

However, the DEM-calibration algorithm also uses tie points [2]. Thus, it is not required to have selected ICESat points located within all datatakes, but to have at least some in the adjacent ones. The simulations in [2] show that complete scenes can be calibrated simply by having two or three datatakes containing around 10-20 height references, located in opposite corners of the adjustment region. Therefore, an analysis focused on equatorial regions has been performed, which calculates the minimal distance between ICESat points independently from the datatake location.

The results of this simulation are shown in Fig. 6. The color coding indicates in this case the distance of an individual ground point to the fourth next ICESat point, after applying the extreme selection criteria. The maximal distance is $70 \mathrm{~km}$. In the rain forests of southern America and southeast Asia, the situation is comparable and not worse.

Since the TanDEM-X DEM will be calibrated in large datatake blocks (at least $\sim 2000 \mathrm{~km} \times 2000 \mathrm{~km}$ ), a relatively uniform distribution of selected ICESat points over any given adjustment region of this size over the Earth is ensured. However, for optimizing the DEM height accuracy, a relaxation of the ICESat selection criteria, as in the analyses in Section III-C, can be useful.

Nevertheless, if the DEM-calibration requirements are not fully met everywhere, an additional backup solution is available. It consists of acquiring dedicated long datatakes with crossing orbits to compensate this reduced density of heightreference information close to the equator. The acquisition of such systematic calibration datatakes is currently not foreseen but could still be integrated in the third year's acquisition plan [1].

\section{E. Selection Criteria for TanDEM-X}

Based on the results in Sections III-B-III-D, and Table IV, the following ICESat selection strategy is proposed for the TanDEM-X mission, which is expected to provide height references with an average accuracy better than $0.53 \mathrm{~m}$. These criteria do not require a priori knowledge of the terrain characteristics and can be automatically applied to the ICESat data.

The first step is to identify the ICESat samples suited for DEM calibration.

1) Outliers preselection with SRTM C-band for points with height difference $>50 \mathrm{~m}$ (threshold configurable). In Polar Regions, uncalibrated TanDEM-X DEMs.

2) Discard samples located in low-coherence regions according to the raw DEM coherence map and water mask.
Then, the extreme selection criteria shall be applied:

3) Echoes with 1 peak and $\sigma<3.2 \mathrm{~ns}$.

The expected resulting subset of height references with relative height accuracies on the order of $0.2 \mathrm{~m}$ can satisfy the TanDEM-X DEM-calibration requirements and even a higher quality level.

For the regions identified in Section III-D, where a lower density of ICESat points is expected, a gradual relaxation of the pulsewidth criteria could be required until the desired selected ICESat point density is reached. The optimal criteria in Table IV are a good empirical threshold set. They allow a slightly wider echo shape while limiting the vegetation coverage density. Selection criterion 3 is then rewritten as follows:

$3^{*}$ ) Echoes with 1 peak and $\sigma<4.9$ ns. Vegetation coverage $<20 \%$.

This results in an increased number of selected points while still maintaining the required height accuracy, as seen in the performed comparisons with the laser DEM in Table IV. Similar height accuracies have been observed in other internal analyses and test regions when applying these selection criteria.

\section{CONCLUSiOn AND OUTLOOK}

The ICESat analyses presented in this paper have provided essential information for the TanDEM-X DEM calibration. The experiment over the test region in Miesbach assisted in the identification of practical global selection criteria for ICESat height samples and offered an estimation of the expected accuracy and density of these selected points on a global scale.

Concerning the outlier removal, simple detection rules have been set, based on the methods of previous publications. In addition, the use of uncalibrated TanDEM-X raw DEMs for this purpose is being investigated. This would be interesting due to its fine horizontal resolution and its obvious unlimited availability.

Furthermore, to achieve the aimed height accuracy, more restrictive selection criteria have been derived, which are based on the return-echo pulse characteristics, listed in its data structure, and on MODIS vegetation coverage data. Only return echoes with very little spread are chosen, which guarantees that no or very few selected ICESat points will lie over forested areas or steep terrain. There, the general accuracy of the samples is considerably smaller than that in flat land, and the discrepancies between an X-band DEM and a laser reflection are the biggest.

The comparison with the laser DEM has confirmed final height accuracies of the selected ICESat data between around 0.2 and $0.5 \mathrm{~m}$. A detailed global coverage analysis proves that a sufficient set of these highly accurate height references remains after applying the selection criteria. In this way, a successful TanDEM-X global DEM calibration is ensured.

\section{ACKNOWLEDGMENT}

The authors would like to thank the E-SAR flight team under the responsibility of R. Horn and the organization of I. Hajnsek for the successful acquisition of the Miesbach interferometric SAR data, and also our colleagues B. Wessel, M. Huber, M. Habermeyer (DLR-DFD), and F. Kurz (DLR-IMF) for 
preparing the Laser DEM from the "Landesvermessungsamt Bayern." The authors would also like to thank the anonymous reviewers for their valuable comments and suggestions to improve this paper.

\section{REFERENCES}

[1] G. Krieger, A. Moreira, H. Fiedler, I. Hajnsek, M. Werner, M. Younis, and M. Zink, "TanDEM-X: A satellite formation for high-resolution SAR interferometry," IEEE Trans. Geosci. Remote Sens., vol. 45 , no. 11 , pp. 3317-3341, Nov. 2007.

[2] J. Hueso Gonzalez, M. Bachmann, G. Krieger, and H. Fiedler, "Development of the TanDEM-X calibration concept: Analysis of systematic errors," IEEE Trans. Geosci. Remote Sens., vol. 48, no. 2, pp. 716-726, Feb. 2010.

[3] J. B. Abshire, X. Sun, H. Riris, J. M. Sirota, J. F. McGarry, S. Palm, D. Yi, and P. Liiva, "Geoscience Laser Altimeter System (GLAS) on the ICESat mission: On-orbit measurement performance," Geophys. Res. Lett., vol. 32, no. 21, p. L21 S02, Nov. 2005.

[4] H. Zwally, R. Schutz, C. Bentley, J. Bufton, T. Herring, J. Minster, J. Spinhirne, and R. Thomas, GLAS/ICESat L2 Antarctic and Greenland Ice Sheet Altimetry Data V001. Boulder, CO: Nat. Snow Ice Data Center.

[5] C. Carabajal and D. Harding, "SRTM C-band and ICESat laser altimetry elevation comparisons as a function of tree cover and relief," Photogramm. Eng. Remote Sens., vol. 72, no. 3, pp. 287-298, Mar. 2006.

[6] L. Magruder, C. Webb, T. Urban, E. Silverberg, and B. Schutz, "ICESat altimetry data product verification at White Sands Space Harbor," IEEE Trans. Geosci. Remote Sens., vol. 45, no. 1, pp. 147-155, Jan. 2007.

[7] H. Zwally, B. Schutz, W. Abdalati, J. Abshire, C. Bentley, A. Brenner, J. Bufton, J. Dezio, D. Hancock, D. Harding, T. Herring, B. Minster, K. Quinn, S. Palm, J. Spinhirne, and R. Thomas, "ICESat's laser measurements of polar ice, atmosphere, ocean, and land," J. Geodyn., vol. 34, no. 3/4, pp. 405-445, Oct./Nov. 2002.

[8] D. Atwood, R. Guritz, R. R. Muskett, C. S. Lingle, J. M. Sauber, and J. T. Freymueller, "DEM control in arctic alaska with ICESat laser altimetry," IEEE Trans. Geosci. Remote Sens., vol. 45, no. 11, pt. 2, pp. 37103720, Nov. 2007.

[9] E. Rodriguez, C. S. Morris, J. E. Belz, E. C. Chapin, J. M. Martin, W. Daffer, and S. Hensley, "An assessment of the SRTM topographic products," Pasadena, CA, Tech. Rep. JPL D-31639, 2005.

[10] H. Duong, R. Lindenbergh, N. Pfeifer, and G. Vosselman, "ICESat full waveform altimetry compared to airborne laser scanning altimetry over The Netherlands," IEEE Trans. Geosci. Remote Sens., vol. 47, no. 10, pp. 3365-3378, Oct. 2009.

[11] R. Bamler and M. Eineder, "Accuracy of differential shift estimation by correlation and split-bandwidth interferometry for wideband and delta-k SAR systems," IEEE Geosci. Remote Sens. Lett., vol. 2, no. 2, pp. 152155, Apr. 2005.

[12] M. Hansen, R. DeFries, J. Townshend, M. Carroll, C. Dimiceli, and R. Sohlberg, "Global percent tree cover at a spatial resolution of 500 meters: First results of the MODIS vegetation continuous fields algorithm," Earth Interact., vol. 7, no. 10, pp. 1-15, Oct. 2003.

[13] GLAS Laser Operation Attributes Table. [Online]. Available: http://nsidc.org/data/icesat/docs/glas_laser_ops_attrib.xls

[14] R. Scheiber, P. Prats, M. Nannini, K. A. C. de Macedo, C. Andres, J. Fischer, and R. Horn, "Advances in airborne SAR interferometry using the experimental SAR system of DLR," in Proc. EURad, Munich, Germany, Oct. 2007, pp. 91-94.

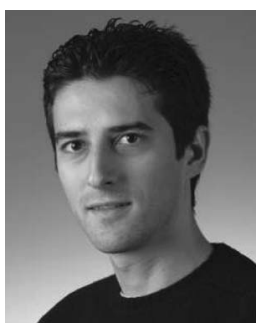

Jaime Hueso González received the M.S. degree in telecommunication engineering from the Polytechnic University of Valencia, Valencia, Spain, in 2003.

From 2004 to 2005, he was a Microwave Engineer with the European Space Agency, Noordwijk, The Netherlands, where he researched on microwave filter design, high-power testing, and multipactor effects on spaceborne microwave waveguides. Since 2006, he has been with the German Aerospace Center (DLR), Wessling, Germany, where he specializes on satellite synthetic aperture radar (SAR) technology. He has been working as a Calibration Engineer for projects like TerraSAR-X, TanDEM-X, and GMES Sentinel-1. His major research interests include the development of innovative calibration concepts for digital elevation models and satellite baseline determination.

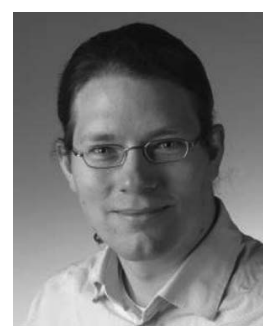

Markus Bachmann received the Dipl.-Ing. degree in electrical engineering from the Technical University of Karlsruhe, Karlsruhe, Germany, in 2005.

Since 2005, he has been with the Microwaves and Radar Institute, German Aerospace Center (DLR), Wessling, Germany, where he is currently a Calibration Engineer in synthetic aperture radar (SAR) calibration. In the TerraSAR-X project, he is responsible for the antenna model calibration and, in TanDEM-X, for the digital elevation model calibration concept.

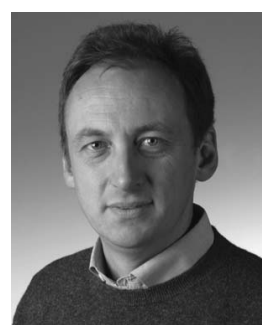

Rolf Scheiber received the Dipl.-Ing. (M.Sc.) degree in electrical engineering from the Technical University of Munich, Munich, Germany, in 1994 and the Ph.D. degree in electrical engineering from the University of Karlsruhe, Karlsruhe, Germany, in 2003 , with a thesis on airborne synthetic aperture radar (SAR) interferometry.

Since 1994, he has been with the Microwaves and Radar Institute, German Aerospace Center, Wessling, Germany, where he developed the operational high-precision interferometric SAR processor for its E-SAR airborne sensor. Since 2001, he has been heading the SAR Signal-Processing Group, SAR Technology Department, where he is currently responsible for the E-SAR campaign data processing, as well as the development of the processing software for the new airborne sensor F-SAR. His current research interests include algorithm development for high-resolution air- and spaceborne SAR focusing, SAR interferometry, differential SAR interferometry, and SAR tomography, as well as radio sounding algorithms and applications.

Dr. Scheiber was awarded as coauthor with the 1996 IEEE Geoscience and Remote Sensing Society Transactions Prize Paper Award for the contribution "Extended Chirp Scaling Algorithm for Air- and Spaceborne SAR Data Processing in Stripmap and ScanSAR Imaging Modes" in 1997.

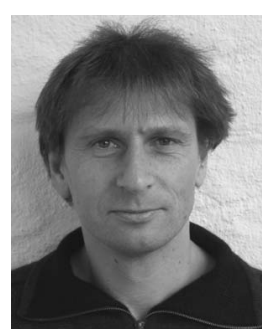

Gerhard Krieger (A'04-M'04-SM'10) received the Dipl.-Ing. (M.S.) and Dr.-Ing. (Ph.D.) degrees (with honors) in electrical and communication engineering from the Technical University of Munich, Munich, Germany, in 1992 and 1999, respectively.

From 1992 to 1999, he was with the LudwigMaximilians University, Munich, where he conducted multidisciplinary research on neuronal modeling and nonlinear information processing in biological- and technical-vision systems. Since 1999, he has been with the Microwaves and Radar Institute, German Aerospace Center (DLR), Wessling, Germany, where he developed signal- and image-processing algorithms for a novel forward-looking radar system employing the principle of digital beamforming on receive. From 2001 to 2007, he led the New SAR Missions Group which pioneered the development of advanced bistatic and multistatic radar systems as exemplified by the forthcoming TanDEM-X mission as well as innovative multichannel SAR techniques and algorithms for high-resolution wide-swath SAR imaging. Since 2008, he has been Head of the new Radar Concepts Department. His current research interests focus on the development of multichannel radar techniques and algorithms for innovative multiple-input-multiple-output SAR systems, the demonstration of novel interferometric and tomographic Earth-observation applications, and the conceptual design of advanced bi- and multistatic radar missions.

Dr. Krieger was the recipient of several national and international awards, including the IEEE Transactions Prize Paper Award of the Geoscience and Remote Sensing Society and the Otto Lilienthal Sabbatical of the DLR. 